\title{
Developing microsurgical milestones for psychomotor skills in neurological surgery residents as an adjunct to operative training: the home microsurgery laboratory
}

\author{
Isaac Josh Abecassis, MD, Rajeev D. Sen, MD, Richard G. Ellenbogen, MD, and \\ Laligam N. Sekhar, MD
}

Department of Neurological Surgery, University of Washington, Seattle, Washington

\begin{abstract}
OBJECTIVE A variety of factors contribute to an increasingly challenging environment for neurological surgery residents to develop psychomotor skills in microsurgical technique solely from operative training. While adjunct training modalities such as cadaver dissection and surgical simulation are embraced and practiced at our institution, there are no formal educational milestones defined to help residents develop, measure, and advance their microsurgical psychomotor skills in a stepwise fashion when outside the hospital environment. The objective of this report is to describe an efficient and convenient "home microsurgery lab" (HML) assembled and tested by the authors with the goal of supporting a personalized stepwise advancement of microsurgical psychomotor skills.
\end{abstract}

METHODS The authors reviewed the literature on previously published simulation practice models and designed adjunct learning modules utilizing the HML. Five milestones were developed for achieving proficiency with each graduated exercise, referencing the Accreditation Council for Graduate Medical Education (ACGME) guidelines. The HML setup was then piloted with 2 neurosurgical trainees.

RESULTS The total cost for assembling the HML was approximately $\$ 850$. Techniques for which training was provided included microinstrument handling, tissue dissection, suturing, and microanastomoses. Five designated competency levels were developed, and training exercises were proposed for each competency level.

CONCLUSIONS The HML offers a unique, entirely home-based, affordable adjunct to the operative neurosurgical education mandated by the ACGME operative case logs, while respecting resident hospital-based education hours. The HML provides surgical simulation with specific milestones, which may improve confidence and the microsurgical psychomotor skills required to perform microsurgery, regardless of case type.

https://thejns.org/doi/abs/10.3171/2020.5.JNS201590

KEYWORDS neurosurgical resident training; education; adjunct training; ACGME milestones; home lab; microsurgery; psychomotor skills

$\Lambda$ LARGE number of overlapping factors currently contribute to creating a challenging environment for neurosurgical residents seeking to develop psychomotor skills in microsurgical technique, including increased treatment of neurological disease with minimally invasive modalities. ${ }^{1-3}$ Yet, microsurgery remains an important tool for the neurosurgeon. Patients referred for open microsurgical treatment often have highly complex lesions not always amenable to endovascular or minimally invasive technologies, ${ }^{4}$ while the in-hospital time required for residents to master the necessary skills is limited by appropriate Accreditation Council for Graduate Medical
Education (ACGME) concerns about patient safety and resident well-being.

Motivated by the further decrease in available training opportunities due to the unfortunate COVID-19 pandemic, 2 residents (I.J.A. and R.D.S.) sought ways to augment their microsurgical psychomotor skills by training at home while on a rotating "shelter at home" order. These residents, with guidance and direction from the senior authors (R.G.E. and L.N.S.), implemented a metered stepwise approach, utilizing a broad series of exercises that incorporated the necessary psychomotor elements to perform microsurgery in their chosen specialty of cerebrovascular

ABBREVIATIONS ABNS = American Board of Neurological Surgery; ACGME $=$ Accreditation Council for Graduate Medical Education; AVM = arteriovenous malformation; bAVM = brain AVM; HML = home microsurgery lab; MCA = middle cerebral artery; NOMAT = Northwestern Objective Microanastomosis Assessment Tool; PGY = postgraduate year; PVA = polyvinyl alcohol; STA = superficial temporal artery.

SUBMITTED May 1, 2020. ACCEPTED May 21, 2020.

INCLUDE WHEN CITING Published online September 4, 2020; DOI: 10.3171/2020.5.JNS201590. 
surgery, culminating with the most complex procedure, the cerebrovascular bypass. In this report, we describe our initial experience with designing and implementing a novel "home microsurgery lab" (HML), developed with the goal of advancing psychomotor skill development and simultaneously respecting ACGME in-hospital educational hours.

\section{Methods}

We used internet resources to establish costs and identify commercially available components for an HML, including a microscope, light source, and instruments. Turkey wings and fruit were sourced from our local grocery store.

The training program was developed through a combined approach that included the following elements: 1) comprehensive literature review to identify articles related to developing competency in cerebrovascular surgery; 2) examination of relevant ACGME core areas and milestones for neurological surgery training; and 3) discussions with the 2 senior authors. We reviewed PubMed to identify relevant articles using the following phrases: "competence in neurosurgery," "competence in aneurysm," "competence in AVM" (arteriovenous malformation), "competence in bypass," "bypass training cerebrovascular," "aneurysm training cerebrovascular," and "AVM training cerebrovascular." In collaboration with and with guidance from the senior authors, drawing on their extensive experience in neurosurgical education in general and open microsurgery in particular, we defined 5 levels of "competency" paralleling the 5 ACGME milestone categories.

The ACGME recognizes competency in 6 core areaspatient care, medical knowledge, practice-based learning and improvement, interpersonal and communication skills, professionalism, and system-based practice-and organizes elements of the core competencies into specialty-specific "milestone" categories, with 5 levels each. Resident trainees are expected to achieve milestone level 4 in all areas prior to graduation. ACGME has developed an appendix for the highest level, level 5, "performing advanced procedures," listing various surgical procedures that qualify as advanced (e.g., superficial temporal arterymiddle cerebral artery [STA-MCA] bypass and petroclival meningioma). ${ }^{5}$ We referred to ACGME core competency and milestone documents extensively to develop the HML training program. We also researched ACGME-mandated graduation minimum requirements in cerebrovascular disease for 2012 to 2020.

We then developed specific HML training exercises to support each level of competency, utilizing models that have been previously reported, including gauze exercises ${ }^{6,7}$ latex for suturing, ${ }^{8}$ polyvinyl alcohol (PVA) tubing, ${ }^{9,10}$ and turkey wing brachial artery models, ${ }^{11}$ and also developed novel techniques using fruit for simulating pial, arachnoid, and tumor capsule dissection. The training program focused on the development of the skills necessary for a broad spectrum of microneurosurgery procedures, albeit cerebrovascular surgeries in particular. The residents piloting the HML (postgraduate year 3 [PGY3] and PGY7) planned to specialize in this area. These residents tested each HML training exercise at each level of compe- tency, recording their experiences and observations; subsequent refinements were made in an iterative fashion, in consultation with the senior authors.

\section{Results}

Components included in the HML are listed in Table 1 and shown in Fig. 1A-C. The total cost for assembling the HML was $\$ 850$; the expense was supported by residency book funds, and supplies were purchased online. Costs can be reduced by sharing the camera $(\$ 240)$ and other supplies between trainees. The camera can be used to upload videos to a secure location for mentors to review.

For medical students, interns, and junior residents ( PGY1-3), we recommend spending approximately 3-4 hours before any HML sessions to become familiar with the instruments, the forces needed to grip the suture, the ideal locations for grasping the needle, efficient knot tying, breathing exercises, upright posture, and economy of movements. These exercises can be performed using the needle holder, suture, tying forceps, jeweler forceps, and a piece of latex or gauze $e^{6,7}$ under the microscope.

Table 2 displays the levels of competency, corresponding training regimens, and specific exercises that were developed. Specific exercises are demonstrated in Figs. $1 \mathrm{D}-\mathrm{H}, 2$, and 3 . We recommend early introduction at level 1 of a holistic program for both the cognitive and technical/psychomotor acquisition of the skill set required for safe, successful microsurgery. This includes a meditation or yoga technique to instill the cognitive tools necessary for performing under conditions of stress, ${ }^{12}$ which are often encountered with challenging neurological CNS pathology associated with complex anatomical considerations. The stress reduction skill also translates to practicing conscious awareness of breathing during HML technique performance. Advancement of familiarity and understanding of neuroanatomy via textbooks and cadaveric dissections is coupled with exercises in the HML. As the trainee advances to middle level 3 ( PGY4-5), the HML techniques transition to the use of more delicate tools (10-0 sutures and jeweler forceps) and 3D planning (i.e., vessel construction from $2 \times 2-$ and $1 \times 2-\mathrm{cm}$ latex pieces). We also introduce the "fruit peel" exercises (Fig. 2), which require 3D tool manipulation, careful dissection of fragile tissue planes (which simulate a subpial tumor resection or preserving a critical arachnoid layer surrounding a tumor), using sharp dissection (simulating the need to cut tumor-feeding arteries) without injuring nearby structures, and careful application of countertension forces without injuring underlying pulp/juice vesicles (which simulate parenchyma). Although there is no validation of these hypothetical "fruit peel" exercises for neurological surgery operations, they require patience, concentration, and sophisticated psychomotor skills. At this stage, we also suggest starting with the PVA tubing, larger diameter ( $3-5 \mathrm{~mm}$ ), to avoid spending time on tissue dissection and maximize the exposure to actual suturing. Additional difficulty can be added by not affixing the tube in place externally. This middle phase also entails initiation of independent training in the cadaver laboratory, which is usually afforded during the research year. 
TABLE 1. Complete list of components for HML

\begin{tabular}{|c|c|c|}
\hline Category \& Items (no.) & Price & URL \\
\hline \multicolumn{3}{|l|}{ Microscope } \\
\hline Amscope $7 x-45 x$ & $\$ 397$ & https://www.amscope.com/7x-45x-trinocular-stereo-zoom-microscope-on-single-arm-boom.html \\
\hline Light source & $\$ 29$ & https://www.amscope.com/white-adjustable-144-led-ring-light-illuminator-for-stereo-microscope-camera.html \\
\hline Camera* & $\$ 240$ & https://www.amscope.com/5mp-usb3-0-real-time-live-video-microscope-digital-camera-1.html \\
\hline \multicolumn{3}{|l|}{ Instruments } \\
\hline $\begin{array}{l}\text { Stainless steel micro- } \\
\text { scissors (1), curved } \\
\text { nonlocking micro- } \\
\text { needle driver (1), fine } \\
\text { forceps ( } 2 \text { : } 1 \text { curved \& } \\
1 \text { straight) } \dagger\end{array}$ & $\$ 65$ & https://www.pocketsuture.com/products/microsurgery-instrument-training-set \\
\hline Jeweler's forceps (2) & $\$ 20$ & https://www.amazon.com/Scientific-Labwares-Stainless-Forceps-Straight/dp/B07V3L4CXY \\
\hline $10-0$ suture $(12-$ pack $) \ddagger$ & $\$ 35$ & https://www.pocketsuture.com/products/4-0-nylon-monofilament-training-sutures-dep3m-hwlwm-8mthf \\
\hline Gloves (200-pack)* & $\$ 13$ & https://www.amazon.com/Disposable-Nitrile-Gloves-Medium-Pack/dp/B07W6R6HD4 \\
\hline $\begin{array}{l}\text { Fruit: blueberries, } \\
\text { grapes, \& oranges* }\end{array}$ & $\$ 5$ & Local grocery store \\
\hline Raw turkey wings (4) & $\$ 5$ & Local grocery store \\
\hline Plastic tray & $\$ 6$ & https://www.amazon.com/Carlisle-CT121603-Standard-Cafeteria-Black/dp/B00BUTZP1E \\
\hline $\begin{array}{l}\text { Cork board for tubing/ } \\
\text { latex/gauze, } 7 \times 7 \text {-inch } \\
(6 \text {-pack })^{*}\end{array}$ & $\$ 16$ & https://www.amazon.com/Juvale-6-Pack-Cork-Trivet-Set/dp/B01N6LKD2J \\
\hline Red dye & $\$ 5$ & https://www.amazon.com/Chef-Van-Food-Coloring-Ounce/dp/B00GURL9CA \\
\hline $\begin{array}{l}\text { Pins to hold gauze/latex/ } \\
\text { arteries in place }(100)^{*}\end{array}$ & $\$ 9$ & https://www.amazon.com/Eisco-Nickel-Plated-Dissection-T-Pins/dp/B00AWS4AYW \\
\hline Gauze sponges $(200)^{*}$ & $\$ 5$ & https://www.amazon.com/Medline-PRM21408CZ-Caring-Non-Sterile-Sponges/dp/B074N8ZX1P \\
\hline $\begin{array}{l}\text { PVA tubing (diameters } \\
0.7,2, \& 4 \mathrm{~mm} \text { ) }\end{array}$ & $\$ 0$ & Donated by local Zimmer-Biomet sales representative; also comes w/ additional 9-0 or 10-0 suture \\
\hline Total cost & $\$ 850$ & \\
\hline
\end{tabular}

Trainees should start to use the microscope for small portions of beginner microdissection.

For upper-level and chief residents (PGY6-7), fellows, and junior attendings, we suggest more emphasis on intraoperative microdissection, using the 0.7 - to 2 -mm-diameter PVA tubes, and transitioning to the turkey wing model with brachial artery dissection (Fig. 3A). It is during these stages (levels 4 and 5) that the anastomoses are practiced rigorously, in a timed fashion, and with evaluation of integrity. For additional difficulty, Fig. 1B shows a cylindrical tube constructed from cardboard to complete microsurgery tasks (fruit, anastomoses, etc.) to simulate working in a corridor of 3,6 , or $9 \mathrm{~cm}$, although this requires additional bayoneted instruments. At all stages, efforts should be made to record the practice on video (anastomoses and otherwise) for the trainee to review techniques independently and with mentors for formal feedback sessions. Similar to the ACGME milestone levels, we consider level 4 the standard goal for graduating chief residents, with level 5 as the goal for motivated chief residents seeking additional time in microsurgery, or postgraduate fellows. Note that there are no specific times for completion, quantity of tasks, or any quantitative metrics in Table 2 , in order to tailor skill development to the individual's abilities and enable milestone achievement for all trainees.

The 4 techniques included in HML practice are 1) identification and dissection of the brachial artery and vein in the turkey leg (to simulate preserving important structures like arteries, veins, and nerves), 2) end-to-end anastomosis using either the turkey brachial artery or silastic tubing, 3) side-to-end anastomosis using either the turkey brachial artery or silastic tubing, and 4) side-to-side anastomosis using either the turkey brachial artery or silastic tubing. The HML practice techniques also include a learning exercise called the U-drill, in which 2 separate turkey brachial arteries are harvested and used to perform 2 end-toside, 1 side-to-side, and 1 end-to-end anastomosis, making a U shape, in the same session (Fig. 3).

The general practice regimen (for all techniques) included 1- to 2-hour sessions (for the bypass exercises), 


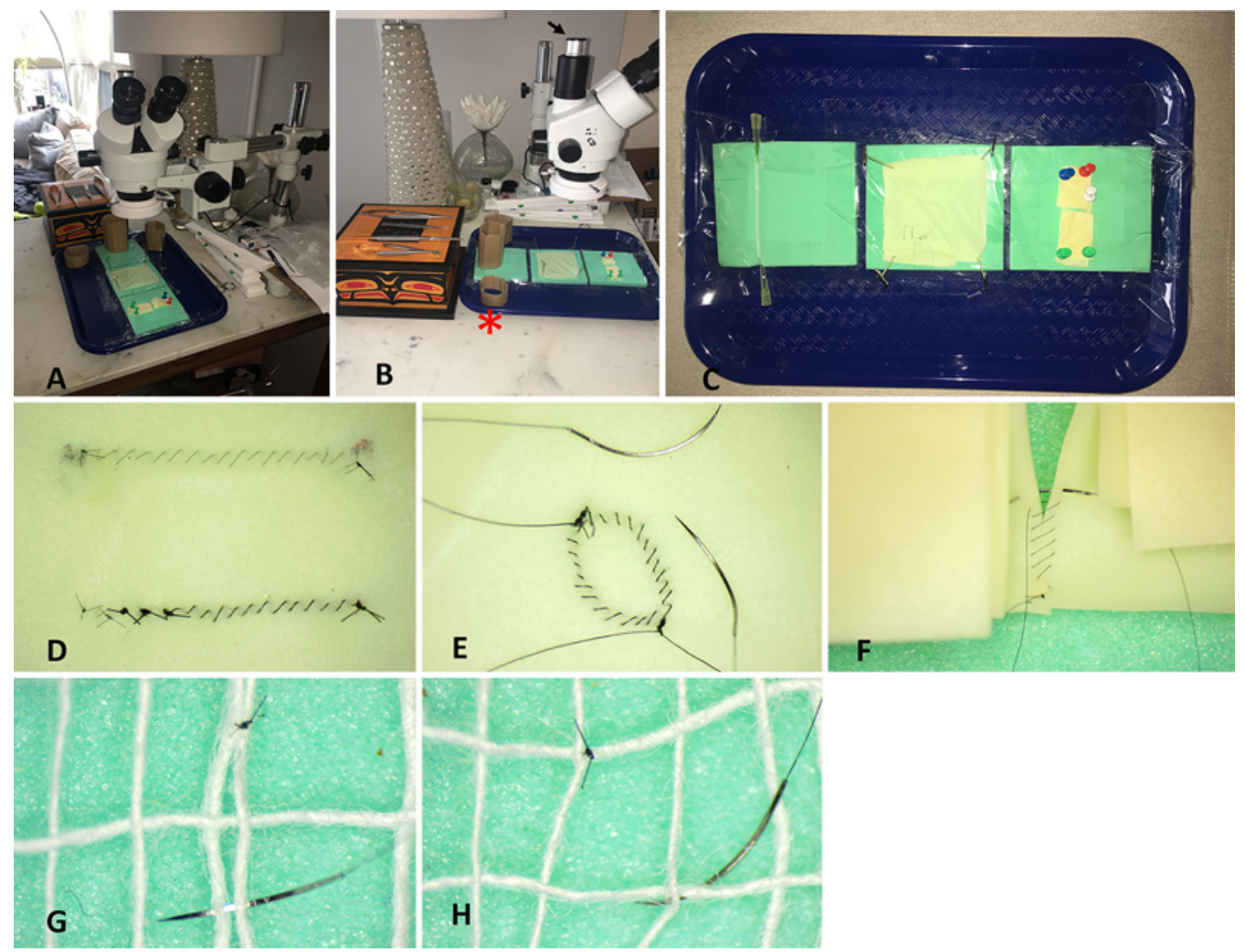

FIG. 1. Fully assembled HML and beginner techniques. A and B: Note the trifocal nature of the microscope, with a dedicated port for capturing still photos or videos (black arrow). Pieces of cardboard have been assembled into 3-, 6-, and 9-cm tubes (red asterisk) to simulate suturing at depth in more advanced training (requires separate bayoneted instruments, available at the time of this report from the vendor listed in Table 1). C: Sample working tray shows 3 foam working pads $(10 \times 10 \mathrm{~cm})$ affixed to the tray with tape, for performing suturing exercises. D and E: "Two-dimensional" suturing exercises, original magnification $8 \times$. D: Running continuous suture on a latex pad $(8 \times 8 \mathrm{~cm})$ in a straight line for $1 \mathrm{~cm}$ (top, 9 to 3 o'clock, 10-0 suture; bottom right, 8-0 suture) and interrupted simple and figure 8 stitches (bottom left, 10-0 and 8-0 sutures). E: Running a simulated pattern for anastomosis with 2 simultaneous needles active, without tangling the suture or damaging needles (8-0 suture). F: Level 2 trainees advance to "3-dimensional" suturing exercises (original magnification $8 \times$ ), suturing with the sequential sewing of layers from deep to superficial using 3 pieces of latex $(7 \times 2 \mathrm{~cm})$ secured to the pad without any tension $(9-0$ suture). Note the importance of eliminating tension in the latex with pins to bring leaflets together. $\mathrm{G}$ and $\mathrm{H}$ : Gauze exercises, original magnification $16 x$. Interrupted knots after suturing adjacent strands of string $(\mathbf{G})$ and corners $(\mathbf{H})$. Figure is available in color online only.

10-15 minutes for dissection and graft extraction, 20-40 minutes for each anastomosis, and 5 minutes for interrogation, with 1-2 sessions per week. We recommend video recording of the initial (pretraining) session of techniques, and posttraining sessions after 12-15, 25, and 50 hours of practice, with formal grading of these sessions via the Northwestern Objective Microanastomosis Assessment Tool (NOMAT) ${ }^{13}$ and formal feedback provided by an experienced faculty surgeon with microsurgical experience. We also suggest documenting time to complete the tissue dissections and bypasses, including graft and donor preparation, but prioritizing quality performance over time until adequate quality microsurgery is performed.

Current and past ACGME cerebrovascular requirements mandated for graduating residents are listed in Table 3.

\section{Discussion}

The current certification and accreditation organiza- tions in neurological surgery are the American Board of Neurological Surgery (ABNS) and the ACGME, respectively. The mission of the ABNS is to "encourage the study, improve the practice, and elevate the standards and advance the science of neurological surgery."14 The ACGME mission is "to improve health care and population health by assessing and advancing the quality of resident physicians' education through accreditation." 15 Both organizations' public health mission to improve the cause of public safety is pertinent to the microsurgical practice exercises executed through the HML. Our overarching goal is to identify practice paradigms that acknowledge this public safety mission and to develop cost-effective, efficient ways to improve microvascular training for the neurological surgery resident.

Over the past several decades, there has been a reduction in the number of patients requiring open craniotomies for the treatment of intracranial aneurysms, brain AVMs (bAVMs), and tumor resections. Evolving, less invasive technologies in endovascular therapy, radiosurgery, and 


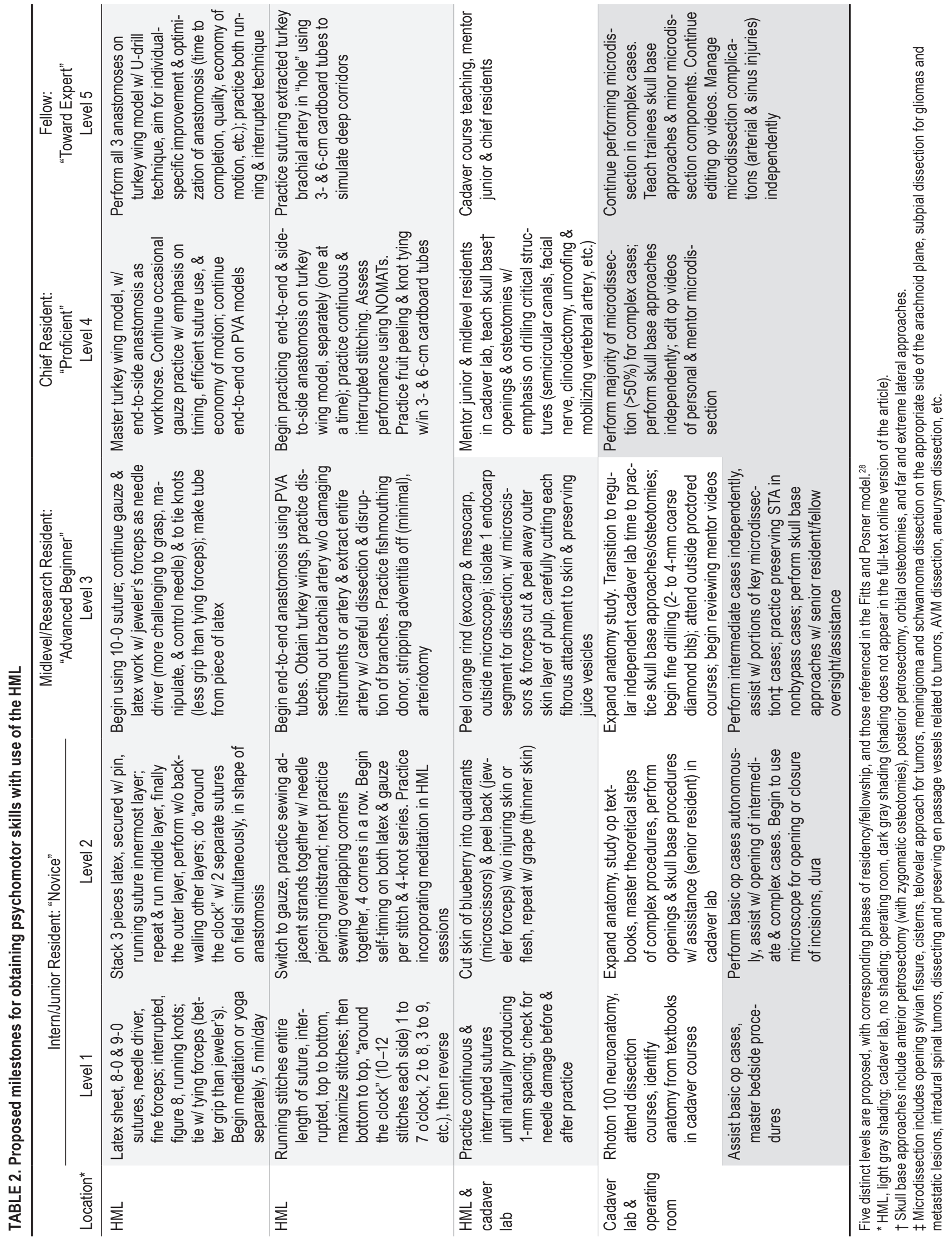



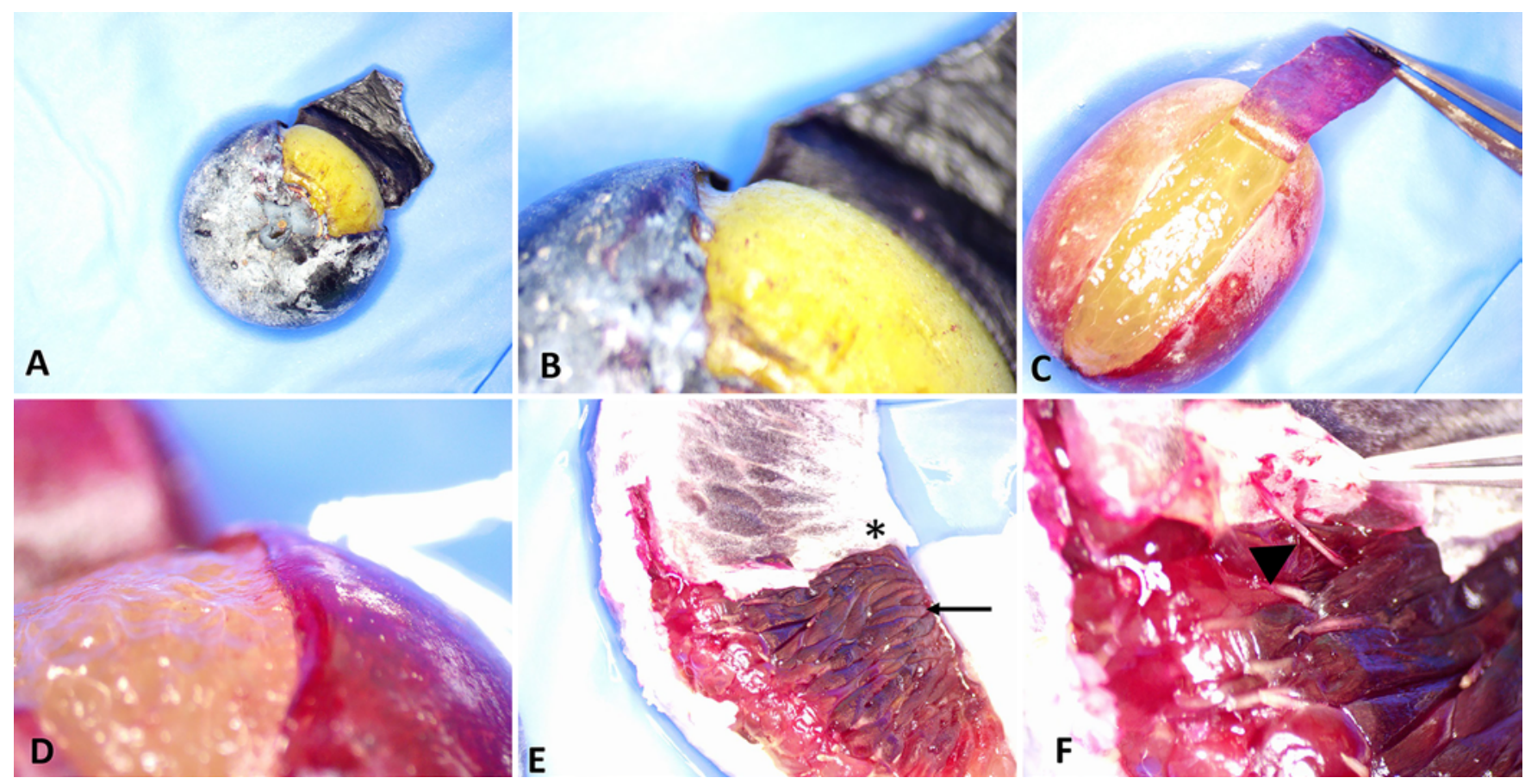

FIG. 2. Peeling fruit model. A and B: The outer skin of a blueberry is incised into approximately a quadrant using microscissors and carefully peeled from the underlying flesh without injuring the skin or fruit. $\mathbf{C}$ and $\mathbf{D}: \mathbf{A}$ grape can be dissected similarly to a blueberry, although the skin is thinner and the axis of dissection is longer, making it more difficult to preserve intact skin. E: A single segment of an orange (or any citrus fruit) endocarp is isolated, and the thin outer skin of the pulp (black asterisk) is incised and carefully peeled away from the juice vesicles (black arrow) to preserve the integrity of both. F: The skin of the segment is anchored via fibrous strands (black arrowhead) to a matrix surrounding the juice vesicles; these strands must be sharply cut using microscissors to advance the dissection. Thus, the microscissors are used (carefully) for the entirety of the citrus fruit dissection. Original magnifications: $3.5 x$ in panels $A, C$, and $E ; 10 x$ in panels $B, D$, and F. Figure is available in color online only.

endoscopic surgery support the safety and efficacy of these modern alternatives. ${ }^{1,2}$ Bypass surgery remains a useful tool for complex aneurysms requiring revascularization, but it is a rare procedure utilized in only approximately $0.4 \%$ of cases across the United States. ${ }^{16}$ The current guidelines for resident education hours and competition among tertiary centers $^{3}$ contribute to the shrinking microsurgical operative training exposure for residents. ${ }^{17}$ For example, Lai and Morgan reviewed an Australian database for total aneurysm cases from 2000 to 2008 and showed a 53.3\% reduction in open craniotomy for the treatment of aneurysms. ${ }^{1}$

\section{Importance of Adjunct Training Modalities}

There is a clear need for developing novel strategies to augment contemporary resident and fellow education for those hoping to advance their psychomotor milestones in a stepwise fashion in microsurgery. While surgical simulation models have been reported, most are lacking in adequate and validated assessment tools $s^{18,19}$ or are purely cadaveric. Thus, surgical simulation is best performed at well-equipped medical institutions and is therefore subject to the ACGME education hour limitations. In addition, these cadaveric laboratories are difficult to employ independently without the immense and expensive resources provided by an institutional microsurgical laboratory, or they have variable fidelity, cost, and feasibility. ${ }^{20}$ In this report, we describe the development of a convenient, low- cost, home-based laboratory with the goal of fostering the psychomotor skill development necessary for microsurgical techniques, consistent with both resident education hour limitations and ACGME milestones.

Traditional surgical training, or "learning by doing," stemmed from the Halsted apprenticeship model, in which the resident learns experientially with intermittent evaluation. This training approach relies on high case volume and extensive time spent in the hospital. However, due to limited resident work hours and other changes in neurological surgery training and practice, this traditional model has become less effective. Chowdhry and Spetzler addressed an important paradigm shift pertaining to training, with a transition from "circumstantial practice" to "intentional practice," in which the loss in volume and hours is compensated for by designing high-yield educational experiences. ${ }^{3}$ In addition, concrete and quantifiable goals and milestones are created to ensure adequate progress. While there have been advances in neurosurgical training that encourage the philosophy of intentional practice, a validated program for concerted practice and evaluation outside of resident case experience is still lacking. Our goal was to provide recommendations for practice using the HML, in addition to microsurgery case volume, and to create a standardized competency scale to support the journey to microsurgical competency (Table 2).

The concept of home-based learning has been de- 

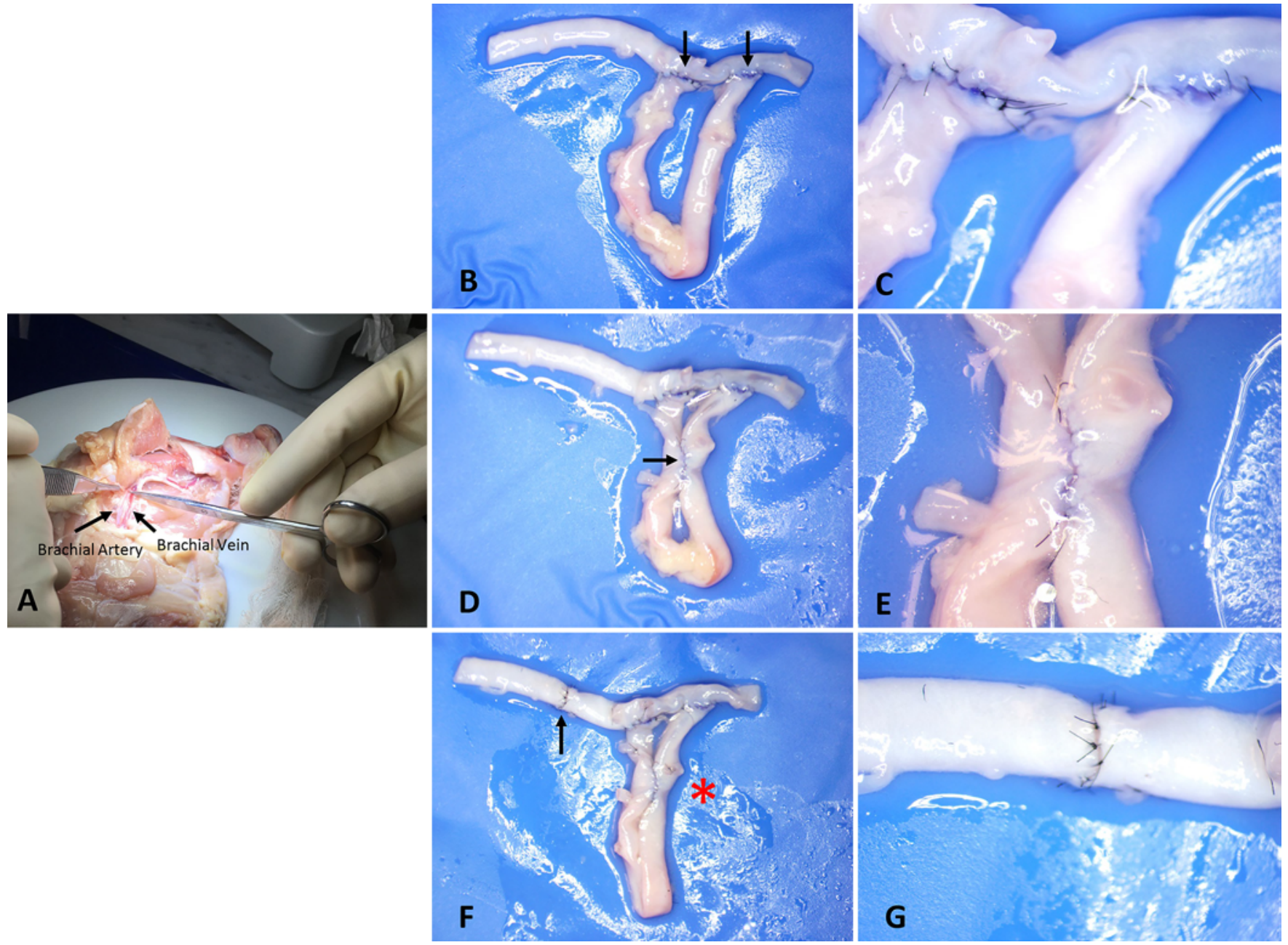

FIG. 3. Turkey wing model for performing the U-drill anastomosis technique. A: Identification and dissection of the brachial artery in the bicipital groove for a total length of 5-6 cm. B-F: U-drill. B and C: The first step in the U-drill is to perform 2 separate endto-side anastomoses (black arrows in B). Note that the anastomosis on the left was performed with interrupted simple and figure 8 stitches, whereas the anastomosis on the right was performed in a running continuous fashion ( $9-0$ suture). D and E: The next step is to perform a side-to-side anastomosis with a running continuous 10-0 suture (black arrow in D). F and G: In the final step, an end-to-end anastomosis is performed with interrupted 10-0 sutures (black arrow in F), with suturing of any side-branch arteries to facilitate graft interrogation (red asterisk in F; 9 total in this sample). Original magnifications: $3.5 \times$ in panels $B, D$, and F; $10 \times$ in panels $\mathrm{C}, \mathrm{E}$, and $\mathrm{G}$. Figure is available in color online only.

scribed in the plastic surgery literature; Malik et al. ${ }^{21}$ showed the viability of technical skill acquisition in medical students using either a home iPad or home microscope setup. A similar notion of home-based learning has been alluded to in the neurosurgical literature, ${ }^{22}$ though the described method was limited to training entirely via suturing strands of gauze, without expansion into more translatable models. Hafez et al. ${ }^{23}$ reviewed important technical pearls for performing cerebral bypass and also suggested a rigorous training curriculum: at least 1 hour per day using 7-0 and 8-0 sutures ( 3 months); another minimum 1 hour per day using 9-0 suture ( 3 months); a minimum 1 hour per day with 10-0 suture, focusing on speed (270 hours to achieve "expertise"); and finally, at least 1 hour biweekly to maintain expertise. We propose an expansion specific to neurosurgical training, with detailed training regimens and guidelines for both home and clinical training, that extends beyond bypass/microsuture training. We also use a variety of models that have been previously reported and validated (at least to some degree), including gauze exercises, ${ }^{6,7}$ latex for suturing, ${ }^{8}$ PVA tubing,, 10 and turkey wing, which provides experience with real tissue handling properties. ${ }^{11}$ We also report a novel tissue dissection exercise using fruit to simulate tumor capsule, arachnoid, and pial dissection. These models all offer low to medium fidelity, low cost, and high feasibility.

Moving forward, it will be important to assess the efficacy of learning obtained through the HML. Dedicated video of both the microscopic field and the trainee (i.e., to grade posture) and review and grading of performance by an experienced senior surgeon at established time points are important because self-assessment alone is inadequate, particularly for novice trainees without adequate knowledge to self-correct errors and self-evaluate. ${ }^{24,25}$ 
TABLE 3. ACGME-mandated minimum graduation requirements in cerebrovascular disease for graduating chief residents over the past decade

\begin{tabular}{|c|c|}
\hline Years & $\begin{array}{c}\text { ACGME Cerebrovascular Minimum Graduation } \\
\text { Requirements }\end{array}$ \\
\hline 2012-2015 & $\begin{array}{l}50 \text { total cases, including } 40 \text { open craniotomies \& } 10 \\
\text { endovascular interventions for cerebrovascular } \\
\text { pathology }\end{array}$ \\
\hline 2015-2019 & $\begin{array}{l}50 \text { total cases (open \& endovascular) for cerebrovas- } \\
\text { cular pathology }\end{array}$ \\
\hline 2019-present & $\begin{array}{l}60 \text { total cases (open \& endovascular) for cerebrovas- } \\
\text { cular pathology, w/ } \geq 10 \text { in open craniotomy }\end{array}$ \\
\hline
\end{tabular}

\section{Competency Versus Proficiency Versus Expertise}

Gélinas-Phaneuf and Del Maestro explored the philosophical and technical paradigms necessary for training expertise. ${ }^{26}$ They emphasize the importance of deliberate practice (as advocated by Ericsson ${ }^{27}$ ) as a goal-oriented method to improve performance and expert feedback, with approximately 10,000 hours required to achieve "expert status" (or high competency). While simple "competence" may realistically be the state of surgical performance for trainees at the time of graduation from residency or fellowship, the goal is to ultimately achieve "expertise" down the road; thus, the targeted initiatives during residency training should reflect that goal.

For effective skill acquisition, Gélinas-Phaneuf and Del Maestro ${ }^{26}$ advocate for combining the Fitts and Posner model $^{28}$ with Vygotsky's zone of proximal development model ${ }^{29}$ describing 4 phases of acquiring expertise: ${ }^{30}$ 1) "novice," where cognitive acquisition of psychomotor skills is the basis (i.e., learning the steps), with significant outside regulation; 2) "advanced beginner," the integrative/associative stage, during which mistakes become more rare and there is rapid skill acquisition and gradual progress in performance, with significant self-regulation; 3) "competent/proficient," where performance has become automatic and tasks can be performed with less active cognitive input; and 4) "expert," a level characterized by seamless responses to foreign, unfamiliar situations and environments, with consistent peak performance. Equally important to achieving expertise is its maintenance; success at this stage relies on a continued commitment to deliberate practice after graduation, while avoiding the routine automaticity encountered in phase 3 . In practice, this translates to self-review of operative videos and refinement of technical skills. ${ }^{3}$ The HML may play a role as an adjunct to these processes at all levels.

We propose that for aspiring microsurgeons, achieving levels 1 and 2 (Table 2) corresponds to novice, level 3 corresponds to advanced beginner, level 4 corresponds to proficient and should be the target during residency, and level 5 represents a dedication to expertise, as obtained either with significant dedicated time during residency (i.e., enfolded fellowship and extra rotations in microsurgery) or with a postgraduate fellowship. Expertise does not come until several years into practice as an attending neurological surgeon, ABNS oral board completion, and subspe-
TABLE 4. Example of suggested training scheme, $\mathrm{HML}$, operating room, and other educational initiatives for obtaining and maintaining expertise in open cerebrovascular surgery

\begin{tabular}{|c|c|c|}
\hline $\begin{array}{l}\text { Level } 5 \text { (toward } \\
\text { expertise) }\end{array}$ & $\begin{array}{l}\text { Expertise } \\
\text { (postgrad) }\end{array}$ & $\begin{array}{l}\text { Maintenance } \\
\text { (per yr) }\end{array}$ \\
\hline HML 50 hrs/yr & $\begin{array}{l}\text { HML } 100 \text { hrs/yr, including } \\
\text { deep suturing }\end{array}$ & $\begin{array}{c}\text { HML } 50 \text { hrs/yr, ideally } \\
10 \text { hrs before each } \\
\text { elective bypass }\end{array}$ \\
\hline $\begin{array}{l}70 \text { aneurysms } \\
\text { (dissection \& } \\
\text { clipping) }\end{array}$ & $\begin{array}{l}140 \text { aneurysms (dissection } \\
\quad \text { \& clipping) }\end{array}$ & 25 aneurysms \\
\hline $\begin{array}{l}10 \text { STA-MCA } \\
\text { bypasses }\end{array}$ & 20 STA-MCA bypasses & 5 bypasses (any kind) \\
\hline 5 bAVMs & $\begin{array}{l}\text { 5-10 high-flow bypasses/ } \\
\text { interposition grafts/ } \\
\text { intracranial-intracranial } \\
\text { bypasses }\end{array}$ & 5 bAVMs \\
\hline Meditation & $10 \mathrm{bAVMs}$ & \\
\hline $\begin{array}{l}\geq 2 \text { formal } \\
\text { proctored } \\
\text { microsurgery } \\
\text { labs }\end{array}$ & $\begin{array}{l}2 \text { yrs self-monitoring clini- } \\
\text { cal outcomes, w/ <20\% } \\
\text { ischemic complication } \\
\text { rate for bypasses }\end{array}$ & $\begin{array}{l}\text { Op major complication } \\
\quad \text { rate }<10 \%\end{array}$ \\
\hline
\end{tabular}

cialty-specific guidelines for quality (see Table 4 for an example of such guidelines for cerebrovascular surgery) are achieved.

As described above, "competence" is a much broader term awarded via the ACGME milestones, in reference to 6 core competencies. Here we propose a milestone framework for achieving first "proficiency" and then "expertise" in microsurgery. This requires dedication inside and outside of the operating room, feedback from an expert microsurgeon mentor, and internal self-regulation, particularly as one progresses during residency and fellowship training. Furthermore, we propose that the HML may also appeal to neurological surgery faculty members who wish to practice and hone psychomotor skills and gain confidence before a particularly challenging procedure, in the comfort and privacy of their home.

\section{HML Within Existing Resident Education Paradigm}

It is important to distinguish the HML from other adjunct training tools (Fig. 4). There is no substitute for learning the underpinnings of neuroanatomy, with specific attention to important neurovascular structures and their relationships to one another in space. This learning process begins with textbook instruction and iteration; for each year of development in residency, more layers of complexity are grasped. ${ }^{31}$ Once a basic understanding of anatomy is built, additional delving into sources with information on surgical steps and rationales is imperative to understanding the goals, steps, pearls, and potential pitfalls associated with specific microsurgical operations. ${ }^{32}$

The next step is the cadaver laboratory, where dissections can be conducted, drilling performed, and vessels, nerves, and structures identified. At our institution, we 


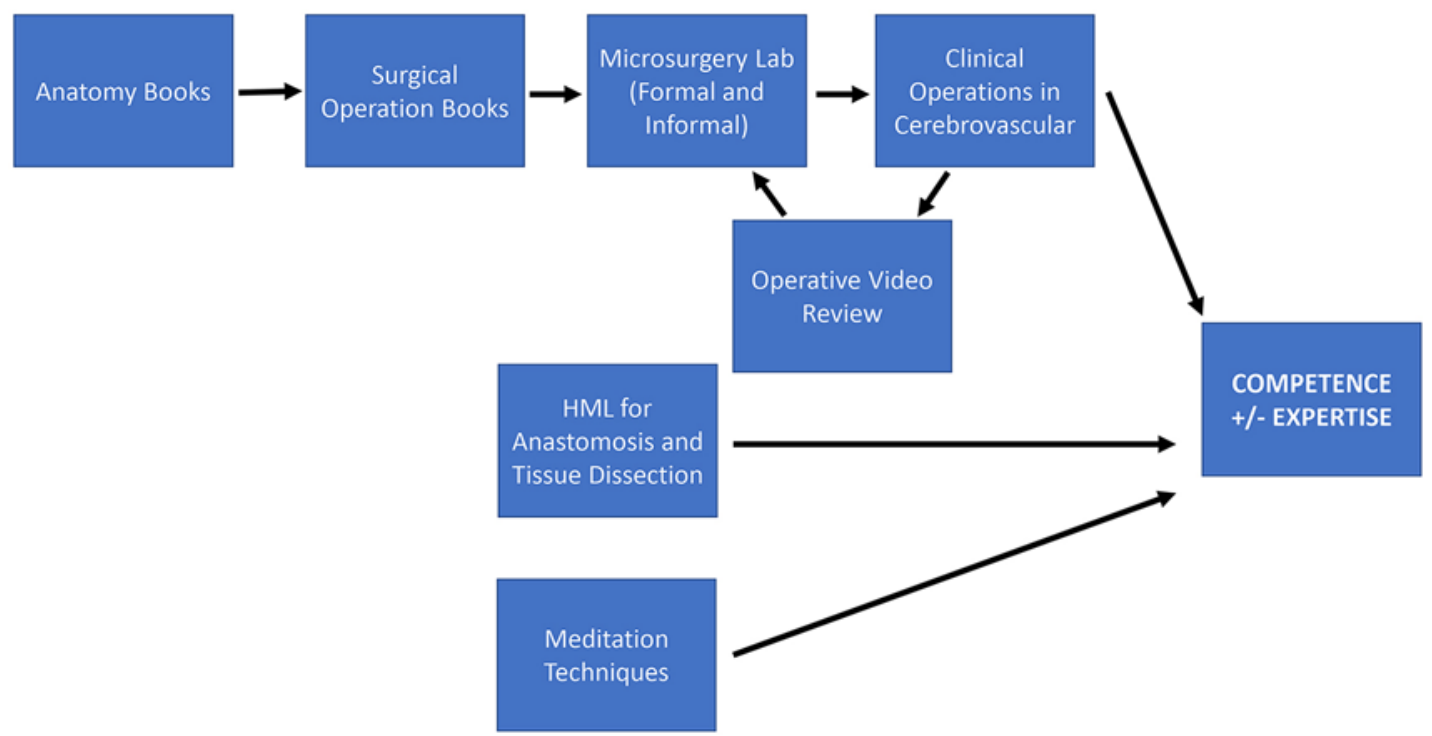

FIG. 4. Schematic diagram showing the position of the HML within the larger picture of resident training in open cerebrovascular education. Figure is available in color online only.

mandate that residents attend approximately 4 formal cadaveric laboratory sessions annually, including full-day sessions dedicated to the anterior, middle, and posterior fossa, cerebral veins, and deep cerebral approaches, and a microanastomosis laboratory session. Furthermore, residents are encouraged to utilize this resource on their own time to practice specific maneuvers encountered in the senior authors' operating room. For example, anterior clinoidectomy with optic canal decompression, transcallosal approaches, orbitotomy and orbitozygomatic osteotomy, anterior petrosectomy, posterior petrosectomy, far and extreme lateral approaches, high carotid neck dissections, and other operative procedures are perfected to enable increased autonomy at the time of surgery. Table 2 outlines this suggested evolution of responsibility in the classroom and cadaver laboratory. We deliberately incorporate skull base techniques into our recommendations for training, as these minimize the need for brain retraction (in addition to cerebrospinal fluid drainage via cistern dissection), optimize visualization of critical structures like cranial nerves and perforators, enhance exposure for ruptured or large and giant aneurysms, expand deep narrow corridors in bypass surgery, and build comfort with venous sinus identification, skeletonization, and repair. We consider the orbitozygomatic approach (and its modifications) and the posterior petrosectomy (or "petrosal") as the expanded workhorses of the anterior, middle, and posterior fossa, when pterional or retrosigmoid approaches seem constricted or inadequate, respectively. Typically, a junior resident pairs with a chief resident, and together they attend the laboratory 3-4 times per month, with a focused agenda. The junior resident practices the basics of exposure, and the chief resident practices more delicate portions of the operation. We advise that at least 2 formal cranial microsurgery courses be taken annually, with expert faculty in attendance to provide direct feedback, and as much additional time as possible spent in the cadaver laboratory practicing techniques independent- ly. These experiences translate to significantly more educational gratification at the time of surgery. Subsequently, there is additional fortification of the educational experience when the chief resident edits the operative video into a succinct "highlights reel," where key maneuvers performed by the resident and attending are identified and presented sequentially, to collectively narrate operating room events. Further refinement of the resident's abilities occurs upon reentering the cadaver laboratory and implementing technique updates gleaned from the operative videos. These processes are distinctly different and complementary to the skills obtained in the HML, which are specifically focused on tissue handling with microinstruments and agility at performing anastomosis techniques.

As trainees begin to subspecialize toward the end of their training, we advise them to work with mentors to develop a quantitative list of cases and approaches that seem appropriate for that specific trainee to operate competently. As an example, a suggested list for level 5 in open cerebrovascular training is shown in Table 4, with additional recommendations for achieving expertise as a junior faculty member and maintaining expertise thereafter. These suggestions include use of the HML and were developed based on the experience of the senior author (L.N.S.), ACGME guidelines, and graduating resident case logs over recent years (Table 3), as well as recent literature on open cerebrovascular volume. ${ }^{33}$

\section{Meditation}

We also advise, in parallel to the HML and simulation/ laboratory exercises, dedicated training for the mind and confidence of the surgeon. Microsurgical operations can be difficult, tedious, and exhausting, both mentally and physically. Suturing a bypass or dissecting a large tumor from adjacent eloquent cortex requires prolonged periods of intense concentration in an already "hyperattentive en- 
vironment," where any lapse in focus may have deleterious consequences. Moreover, the neurosurgeon is the leader within the operating room, constantly expected to perform, direct, and coordinate his or her surgical assistant, anesthesia colleagues, nursing staff, and neuromonitoring team. The surgeon must inspire the team, explain expectations and objectives, manage crises with a calm demeanor, and ultimately accomplish the goals of the operation efficiently and safely. The senior author (L.N.S.) has found success in these tasks through regular meditation, with an emphasis on breathing exercises and control of thought and emotions (which paradoxically begins with building comfort around not actively controlling one's thoughts and emotions). There are applications available for developing routine meditation practices, for example, Calm (www. calm.com) and Headspace (www.headspace.com), the latter of which has been generously made available free to all physicians at our institution during the COVID-19 health crisis. We strongly believe that regular meditation or any cognitive exercise of the learner's choice translate to improved performance in complex microsurgical technique acquisition and performance. ${ }^{12}$ Meditation practice can be easily integrated with HML exercises in the privacy of the home-based learning environment.

\section{Conclusions}

We propose the HML as an adjunct to microsurgical simulation training and ACGME and ABNS operative case $\operatorname{logs}$ for all neurosurgery residents to help them achieve proficiency and expertise in microsurgery. While some of the milestones and laboratory-based practices utilized to develop the HML described in this report are cerebrovascular in nature, these milestones were developed to advance learners' skills in microsurgery for all procedures and for all neurosurgeons, regardless of their focus and level of experience. Of equal importance to achieving expertise is maintenance, which requires diligent commitment and can be advanced through the HML.

\section{Acknowledgments}

The authors appreciate the assistance of Sharon Durfy, PhD, with manuscript preparation.

\section{References}

1. Lai L, Morgan MK. The impact of changing intracranial aneurysm practice on the education of cerebrovascular neurosurgeons. J Clin Neurosci. 2012;19(1):81-84.

2. Abecassis IJ, Zeeshan Q, Ghodke BV, et al. Surgical versus endovascular management of ruptured and unruptured intracranial aneurysms: emergent issues and future directions. World Neurosurg. 2020;136:17-27.

3. Chowdhry SA, Spetzler RF. Genealogy of training in vascular neurosurgery. Neurosurgery. 2014;74(suppl 1):S198-S203.

4. Lawton MT, Lang MJ. The future of open vascular neurosurgery: perspectives on cavernous malformations, AVMs, and bypasses for complex aneurysms. J Neurosurg. 2019;130(5): 1409-1425.

5. Accreditation Council for Graduate Medical Education. Neurological Surgery Milestones. ACGME. Accessed June 24, 2020. https://www.acgme.org/Portals/0/PDFs/Milestones/ NeurologicalSurgeryMilestones.pdf
6. Inoue T, Tsutsumi K, Adachi S, et al. Effectiveness of suturing training with 10-0 nylon under fixed and maximum magnification (x 20) using desk type microscope. Surg Neurol. 2006;66(2):183-187.

7. Indo M, Tsutsumi K, Shin M. The practice of knots untying technique using a 10-0 nylon suture and gauze to cope with technical difficulties of microvascular anastomosis. World Neurosurg. 2011;75(1):87-89.

8. Lahiri A, Lim AY, Qifen Z, Lim BH. Microsurgical skills training: a new concept for simulation of vessel-wall suturing. Microsurgery. 2005;25(1):21-24.

9. Atlan M, Lellouch AG, Legagneux J, et al. A new synthetic model for microvascular anastomosis training? A randomized comparative study between silicone and polyvinyl alcohol gelatin tubes. J Surg Educ. 2018;75(1):182-187.

10. Mokhtari P, Tayebi Meybodi A, Lawton MT, et al. Transfer of learning from practicing microvascular anastomosis on silastic tubes to rat abdominal aorta. World Neurosurg. 2017;108: $230-235$.

11. Abla AA, Uschold T, Preul MC, Zabramski JM. Comparative use of turkey and chicken wing brachial artery models for microvascular anastomosis training. J Neurosurg. 2011; 115(6):1231-1235.

12. Muhammad S, Lehecka M, Huhtakangas J, et al. Meditation music improved the quality of suturing in an experimental bypass procedure. Acta Neurochir (Wien). 2019;161(8):15151521.

13. El Ahmadieh TY, Aoun SG, El Tecle NE, et al. A didactic and hands-on module enhances resident microsurgical knowledge and technical skill. Neurosurgery. 2013;73(suppl 1):51-56.

14. American Board of Neurological Surgery. Mission, Vision, Values \& Finances. ABNS. Accessed August 13, 2020. https: //www.abns.org/mission-vision-values-2/

15. Accreditation Council for Graduate Medical Education. About Us. ACGME. Accessed June 24, 2020. https://www. acgme.org/About-Us/Overview

16. Sharma M, Ugiliweneza B, Fortuny EM, et al. National trends in cerebral bypass for unruptured intracranial aneurysms: a National (Nationwide) Inpatient Sample analysis of 1998-2015. Neurosurg Focus. 2019;46(2):E15.

17. Piazza M, Nayak N, Ali Z, et al. Trends in resident operative teaching opportunities for treatment of intracranial aneurysms. World Neurosurg. 2017;103:194-200.

18. Patel EA, Aydin A, Cearns M, et al. A systematic review of simulation-based training in neurosurgery, part 1: cranial neurosurgery. World Neurosurg. 2020;133:e850-e873.

19. Gnanakumar S, Kostusiak M, Budohoski KP, et al. Effectiveness of cadaveric simulation in neurosurgical training: a review of the literature. World Neurosurg. 2018;118:88-96.

20. Dumestre D, Yeung JK, Temple-Oberle C. Evidence-based microsurgical skill-acquisition series part 1: validated microsurgical models - a systematic review. J Surg Educ. 2014; 71(3):329-338.

21. Malik MM, Hachach-Haram N, Tahir M, et al. Acquisition of basic microsurgery skills using home-based simulation training: a randomised control study. J Plast Reconstr Aesthet Surg. 2017;70(4):478-486.

22. Chung SB, Ryu J, Chung Y, et al. An affordable microsurgical training system for a beginning neurosurgeon: how to realize the self-training laboratory. World Neurosurg. 2017; 105:369-374.

23. Hafez A, Raj R, Lawton MT, Niemelä M. Simple training tricks for mastering and taming bypass procedures in neurosurgery. Surg Neurol Int. 2017;8:295.

24. Dumestre D, Yeung JK, Temple-Oberle C. Evidence-based microsurgical skills acquisition series part 2: validated assessment instruments-a systematic review. J Surg Educ. 2015;72(1):80-89. 
25. Steiger HJ. Training of cerebrovascular specialists: the surgeon's view. Acta Neurochir Suppl (Wien). 2018;129:129-134.

26. Gélinas-Phaneuf N, Del Maestro RF. Surgical expertise in neurosurgery: integrating theory into practice. Neurosurgery. 2013;73(suppl 1):30-38.

27. Ericsson KA. An expert-performance perspective of research on medical expertise: the study of clinical performance. Med Educ. 2007;41(12):1124-1130.

28. Fitts PM, Posner MI. Human Performance. Brooks/Cole Publishing Company; 1967.

29. Vygotsky LS. Mind in Society: The Development of Higher Psychological Processes. Harvard University Press; 1978.

30. Dunphy BC, Williamson SL. In pursuit of expertise. Toward an educational model for expertise development. Adv Health Sci Educ Theory Pract. 2004;9(2):107-127.

31. Rhoton AL. Rhoton Cranial Anatomy and Surgical Approaches. Lippincott Williams \& Wilkins; 2003.

32. Fessler RG, Sekhar LN, eds. Atlas of Neurosurgical Techniques. Thieme; 2006.

33. Fredrickson VL, Strickland BA, Ravina K, et al. State of the union in open neurovascular training. World Neurosurg. 2019;122:e553-e560.

\section{Disclosures}

The authors report no conflict of interest concerning the materials or methods used in this study or the findings specified in this paper.

\section{Author Contributions}

Conception and design: Sekhar, Abecassis, Ellenbogen.

Acquisition of data: Abecassis, Sen. Analysis and interpretation of data: Abecassis, Sen. Drafting the article: Sekhar, Abecassis, Ellenbogen. Critically revising the article: Abecassis, Sen, Ellenbogen. Reviewed submitted version of manuscript: all authors. Approved the final version of the manuscript on behalf of all authors: Sekhar. Study supervision: Sekhar, Ellenbogen.

\section{Correspondence}

Laligam N. Sekhar: University of Washington, Seattle, WA. respub3@uw.edu. 